\title{
Principal agent relationships and the efficiency of hospitals
}

\author{
Martijn Ludwig · Frits Van Merode • \\ Wim Groot
}

Received: 30 September 2008/ Accepted: 10 July 2009/Published online: 5 August 2009

(C) The Author(s) 2009. This article is published with open access at Springerlink.com

\begin{abstract}
The efficiency of hospitals is an important political issue and has been the subject of a number of studies. Most studies find evidence for inefficiency but provide no theoretical explanations for differences in efficiency. This study used principal agent theory to explain differences in efficiency between hospitals. Two agency issues are examined: (1) quality of care in the relationship between hospital and patient, and (2) internal organisation, i.e. the relationship between the hospital and its main departments. It was found that efficiency and quality go together. This implies that the potential harmful information asymmetry between hospitals and patients does not appear to be a major problem, because increasing efficiency does not seem to reduce quality. Further, we find no relationship between the efficiency of departments and the efficiency of the entire hospital. The interest of hospital departments is currently not in line with the interests of the entire hospital.
\end{abstract}

Keywords Principal agent relationships - Efficiency ·

Hospitals $\cdot$ Stochastic frontier estimation

JEL Classification D2 $\cdot$ I1

\section{Introduction}

In 2008, the total budget for health care was about $10 \%$ of GNP in the Netherlands and it is growing rapidly. This

M. Ludwig · F. Van Merode $\cdot$ W. Groot $(\bowtie)$

Department of Health, Medicine and Life Sciences,

Maastricht University, P.O. Box 616, 6200 MD Maastricht,

The Netherlands

e-mail:w.groot@beoz.unimaas.nl alone could explain the recent interest in the costs and efficiency of health care among both politicians and researchers. But this interest is certainly not new, and a variety of instruments have been applied to gain insight into factors relating costs and efficiency in health care. To analyse efficiency, advanced econometric tools, such as Stochastic Frontier Analysis (SFA) - independently introduced by Aigner et al. [1] and Meussen and van den Broeck [23] — and Data Envelopment Analysis (DEA), have been used. Zuckerman et al. [34], Skinner [30], Newhouse [25] and Dor [9] first introduced SFA to the hospital sector in 1994. Numerous studies have since applied SFA in a hospital setting (see [13] for a review). Ludwig et al. [21] provide the first study applying SFA to estimate the efficiency of Dutch hospitals. Studies using SFA, and also DEA, have the advantage over studies using classical cost functions that they compare hospitals with the best-performing instead of with average-performing hospitals. However, they use the assumption of "classical economic theory" that organisations strive to realise one common goal and that factors relating to agency issues that could explain differences in costs and efficiency are not addressed.

In this study, we examine how factors related to agency issues explain differences in costs, efficiency and quality using SFA. The principal agent framework is used to define hypotheses regarding these explanations. In economic theory, an agency relationship is defined as an agreement in which the principal delegates certain responsibilities to the agent for which the agent receives a certain reward [16]. The agency literature emphasises that the agent has his own utility function, which he maximises. This utility function may coincide partly with the utility function of the principal, but may also differ. The agent will then let his own utility function prevail. The key issue in this relationship is 
the information asymmetry between the agent and the principal. According to Arrow [2], this asymmetry can have two advantages for the agent. The first occurs because the principal cannot evaluate whether the agent lets his own utility function prevail. Secondly, as the productivity of the agent can be measured only by indicators, the principal cannot judge whether the agent acts in the interest of the principal, or just tries to optimise the indicators. Some examples show where agency issues arise in hospitals, and how information asymmetry plays a role:

- The relationship between the hospital (more specifically the medical specialist) and the patient. The patient (the principal) has a health problem and delegates the problem to the medical specialist (the agent). For the patient, it is hard to judge how well he is treated by the medical specialist.

- Inside the hospital, the hospital board (the principal) hires medical specialists (agents) to treat patients. The hospital board is not as well informed about the quality, efficiency and effectiveness of the treatment as the medical specialist is.

- Inside the hospital, another principal agent relationship exists, in the relationship between the hospital board (the principal) and departments, e.g. the ward and the radiology departments (the agents). Again the manager of, for example, the radiology department is much better informed about the quality and necessity of performing an X-ray than the hospital management.

In this study, we analyse two of these relationships empirically and use them to explain hospital efficiency. The first concerns the relationship between the hospital and the patient. Second, we analyse the relationship between the hospital management and departmental managers. The third relationship, that between hospital managers and doctors, is not analysed further. Not because this relationship is not interesting - it is very interesting indeed - but because good quality data on the productivity of medical specialists are not available.

Hospital-patient relationship from an agency perspective

The relationship between a hospital and a patient can be described within a typical principal agent framework. The patient has to rely on the specialised knowledge of the doctor and there is an asymmetry in information about the treatment of the health problem. It is difficult for the patient to measure the performance of the hospital. The hospital might thereby prefer to optimise its own utility function, minimising costs as is mostly assumed in efficiency studies. This may come at the cost of the utility of the patient, who has an interest in receiving high quality care.
The reasoning of Newhouse [25] is in line with this assumed relationship. He states that differences in efficiency might be attributed completely to differences in (unobserved) quality. Many other studies have emphasised the need to include quality measures in efficiency studies. Jacobs and Dawson [15], for example, criticise current methods of efficiency measurement in hospitals, because quality measures are not taken into account. This latter study [15] and others (e.g. Fizel and Nunninkhoven [12]) argue that an increase in the quality of health care is likely to require additional inputs per unit of output, thereby implying lower relative efficiency for higher quality providers.

In contrast with the criticism of frontier studies that differences in inefficiency may simply reflect quality differences, studies that are more management- and organisation-orientated, argue that quality and efficiency complement each other. Porter and Olmsted Teisberg [26], for example, state that: "in health care, as in most industries cost and quality can improve simultaneously as providers prevent errors, boost efficiency, and develop expertise." Similar reasoning is found in Van Merode et al. [32], who argue that departments in a hospital often strive to optimise their own functioning independently of other departments. From the hospital point of view, this is suboptimal. Hospitals that do not optimise follow a more integrative approach where the hospital is organised toward the client (focussed factories). In this approach, quality and efficiency problems are solved simultaneously. This reasoning finds its origin in target engineering, where quality and price preferences form the starting point in engineering services, products and production systems. Van Merode [31] states that this kind of organisation leads to better quality from the perspective of the client, and higher efficiency because the number of transfer points is minimised and learning can be performed systematically. This latter reasoning does not imply that principal agent issues do not arise between hospitals and patients. It does imply that the utility functions of hospitals and patients do not differ that much. The patient wants high quality of care. The hospital will be concerned primarily with efficiency, but this is positively associated with quality.

In short, we can state that, because of asymmetric information between patients and doctors, hospitals might economise on quality to gain efficiency. However, this behaviour might not occur if hospitals that are efficient also deliver good quality care. Therefore, we hypothesise that hospital efficiency and quality go together.

Internal organisation: the relationship between the hospital and its departments

Within hospitals, interests may differ. To gain a good understanding of these different interests within hospitals, 
it is useful to describe hospital organisation. Van Merode [31] states that most hospitals "have a functionalistic structure: surgeons in the surgery department, clinical chemistry in the laboratories, etc."

Most Dutch hospitals are organised as a functionalistic organisation of medical disciplines and facilitating departments as shown in Fig. 1. According to Van Merode et al. [32], this functionalistic organisation implies that it is difficult to realise integration. To gain insight into the different utility functions of hospitals and departments we need to understand how Dutch hospitals are financed.

Hospitals in the Netherlands receive a budget from the government. This budget is based mainly on the number of:

- beds;

- medical specialists;

- outpatients;

- day care patients;

- inpatients;

- ward days.

Within the hospital, the budget is divided between the departments by the hospital management. The amount of this budget is usually fixed for a year. Over the years, variations in departmental budgets depend on the number of (intermediate) products delivered by the departments, for example, the number of ward days by the ward and the number of X-rays by the radiology department. Principal agent issues in the hospital can be understood from this perspective. The hospital board (the agent) may be assumed to strive toward efficient treatment of all patients, physicians may strive toward efficient treatment of the patients within their medical discipline, while departments may strive toward efficient production of their own intermediate products. This optimisation of intermediate products might interfere with the interests of the hospital as it strives toward efficient client treatment. For example, the ward might prefer efficient ward days, because the internal budget system works that way. Efficient ward days are partly in the interest of the hospital management as well. However, the hospital may also aim to shorten the length of stay, which may interfere with the interests of the ward. This implies that departments that are efficient, as measured by their own output, do not in fact contribute to the efficiency of the hospital. Our second hypothesis is that hospital efficiency and departmental efficiency are only partly related.

As Herzlinger [14] argues, there is no or little relationship between the inefficiency of departments and the inefficiency of the total hospital: losses in one part of the organisation are compensated by profits gained in other parts. The nature of planning in hospitals has many similarities with those of job shops. Departments are concerned only with maximising the efficiency of their own processes. The same reasoning can be found in Van Merode [31], who states that, in a functionalistic organisation, departments put their professionals at the centre: everything is organised around the health care professional, not around the patient.
Fig. 1 The hospital as a functionalistic organisation

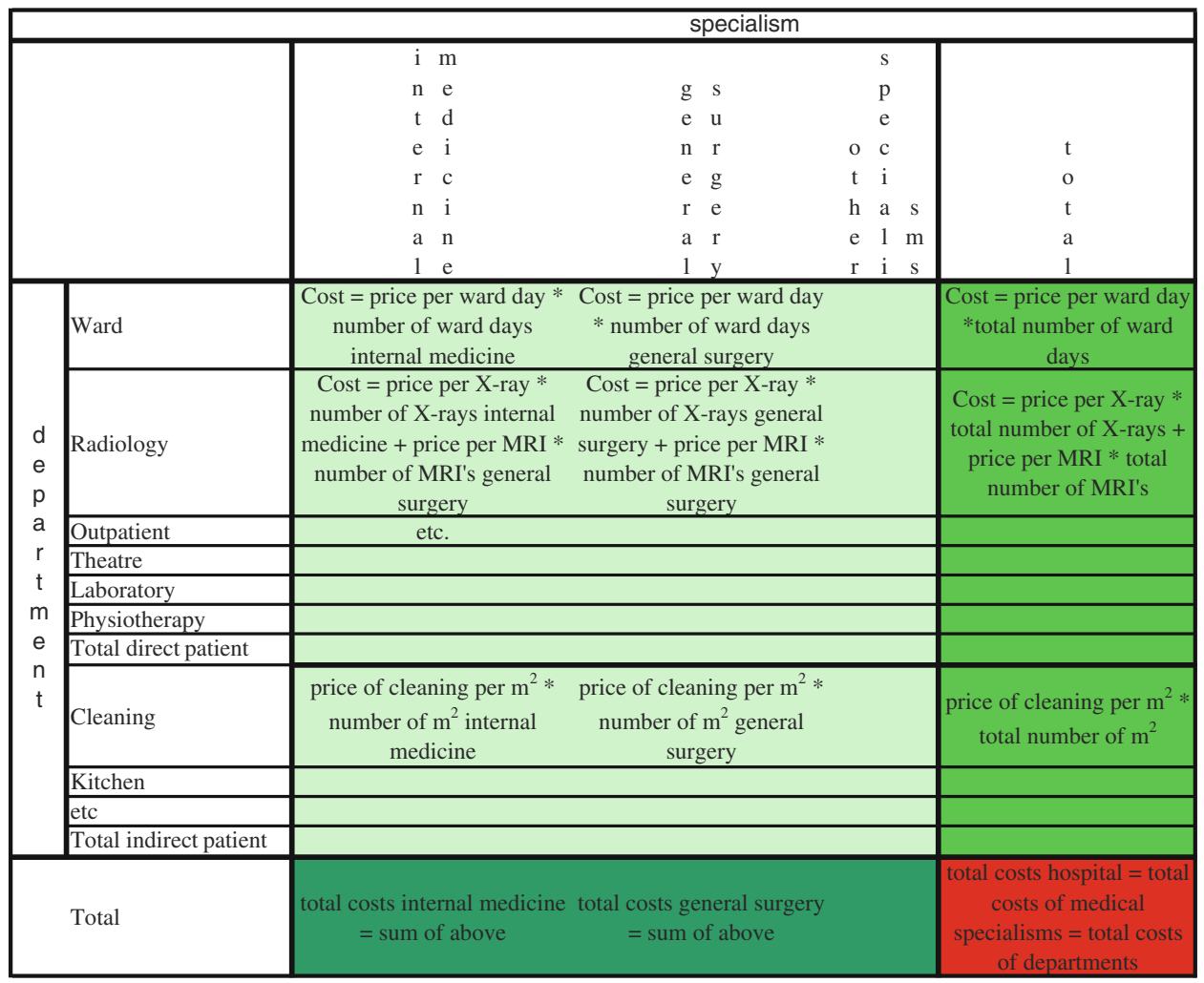


This leads to our third hypothesis: there is no relationship between the efficiency of different hospital departments.

\section{Data}

For this study, we used a database constructed from annual national hospital inquiries on financial, personnel and production data. This database includes data for all 118 Dutch general hospitals. Because of mergers and/or missing data, our dataset consists of 108 cross-sections with 424 observations in total for the years 1998-2002.

One of the main reasons for the lack of studies examining the efficiency of hospital departments may be the lack of available data with which to perform this kind of analysis. In the Netherlands, however, data are available at department level. We use these data to examine the efficiency of hospital departments. Complete data are not available for all departments. Therefore the number of observations per department can be less than 424 .

This section describes the main input and output parameters of our study.

\section{Input prices}

The usual inputs for hospitals are capital, staff and materials. First, we discuss the price of capital. Capital is most frequently measured by the costs of depreciation and interest divided by a measure of the size of the hospital, mostly the number of beds (see, for example, [34, 28]). In the Dutch capitation system for hospitals, capital for investments in buildings is provided by the government under strict regulations. Both the investments in capital and the loans for these investments have to be approved by the Dutch government. Once approved, these costs are financed by the Dutch government. Hospital management thus has little influence over capital costs. Because of this, the price of capital is of little interest from a managerial perspective. Therefore, we exclude costs and capital prices from this study.

Second, we discuss the price of staff. We distinguish six categories of staff: administrative staff, technical staff, support staff (for example psychologists and physiotherapists), nurses, student nurses, and external staff. Since external staff is a broad category and represents less than $3 \%$ of total staff, this category is left out of this study. Administrative and technical staff are combined into one category to obtain a category with a significant size (about $5 \%$ of total staff). The price of staff is not directly available. It is calculated by dividing the total amount spent on staff by the number of full-time equivalents. A price parameter of staff is included in the analysis of each department if the number of staff in the category is above $5 \%$ of the total number of staff.
A large fraction of hospital costs, approximately $60 \%$, is the cost of staff, mainly wages. A debatable issue in efficiency studies is whether the price of staff is exogenous or endogenous to the hospital. To measure the price of staff, two approaches can be distinguished in efficiency studies. In the first approach, the average price of the individual hospital is used. In this approach, wages are assumed to be exogenous to the hospital. In the second approach, the average national price is used. In this approach, the difference between the average national wage and the average wage of the individual hospital is assumed to be endogenous to the hospital. This study assumes wages to be exogenous since the most wages are determined by central negotiations between the labour unions and the Dutch National Association of Hospitals. A third, more sophisticated, approach would be to use regional prices. Regional differences in prices are exogenous to hospitals, while differences between regional and actual prices are endogenous to the hospital. Regional differences in prices can be estimated by a regression equation using time dummies and regional dummies (in the Netherlands, 27 health regions are distinguished). We have estimated these equations. The results show that, in general, there are no significant price differences between regions. This finding is in line with the study of Blank et al. [5], who use a comparable dataset for earlier years. Therefore, in this study, regional differences in prices are ignored.

Third, in addition to the prices of capital and staff, the price of materials is an input parameter. In the dataset, total costs of materials are available. Separate information on prices and quantities is not available. In order to estimate the price of material, a unit price is chosen in the base year 1998. In subsequent years, the price of material is calculated by adjusting prices by the price index for government expenditure in the Netherlands [6].

\section{Departments}

This study distinguishes the following direct patient treatment departments within a hospital:

1. ward;

2. outpatient department;

3. operating theatre;

4. radiology;

5. laboratory;

6. physiotherapy.

\section{Costs}

The dataset contains information on the number of staff per category per department. Of each category of staff, the average annual wage is calculated per hospital. The costs of staff per department are calculated by multiplying the 
average price per staff by the number of staff members. This provides the direct costs of staff per department.

Because of differences in organisational structures and differences in calculation methods between hospitals, it is necessary to make an assumption about the allocation of the costs of indirect staff members, such as the costs of administration and technical staff. The costs of nurses and student nurses are allocated to the direct patient treatment departments based on the number of FTE nurses at the direct patient treatment departments. The costs of other staff are allocated to the direct patient treatment departments based on the total number of FTE at the direct patient treatment departments. On average, we see that the majority of costs of staff $(73.9 \%$ of total wage costs, varying from at most $74.6 \%$ in 1999 to at least $72.8 \%$ in 2002) concern costs of direct staff.

The costs of materials per department are not directly available. The Dutch national cost-calculation scheme for calculating the costs of materials per department is used. This calculation scheme has been developed to introduce casemix-based funding in the Netherlands. It provides guidelines to allocate costs of materials to direct patient treatment departments. For example, allocation of the costs of cleaning is based on the number of square metres per department. Since it is obligatory for hospitals to have an extensive cost administration, we are able to use a detailed allocation.

In general, about $40 \%$ of total costs are costs of materials. In the operating theatre and radiology department, the costs of materials are more than $50 \%$ of total costs. The standard deviation is relatively low compared to the average. No large differences between hospitals in the percentage of material costs per department are found. Including the allocated costs, the six departments distinguished in this study cover, on average, more than $90 \%$ of total hospital costs (excluding costs of capital). As argued above, the costs of capital for buildings are left out of the analysis. This implies that, on average, $12 \%$ of the total costs is left out of the analysis.

\section{Outputs}

\section{Hospital}

To measure the output of hospitals, five output parameters are used. First, Diagnostic Related Group (DRG)-weighted admissions are used. Although the DRG system was developed more than 25 years ago by Fetter et al. [11], this method of measuring output is new for Dutch hospitals. In 2002, a Dutch version of the IR-DRG grouper was developed, which is used in this study. The Dutch version of the IR-DRG grouper uses the ICD-9 diagnosis codes and Dutch CVV procedure codes, which are quite similar to ICD procedure codes.
This study uses the Dutch DRG cost-weights calculated by Vandermeulen et al. [33] for both admissions and daycare admissions. Since no DRGs exist for outpatient visits, the non-weighted number of first outpatient visits is additionally used as an output measure.

Besides curing patients, hospitals have two other important outputs: research and teaching. Research is done mainly in university hospitals, which are excluded from this study. On the contrary, teaching is performed by 83 of the 108 non-university hospitals represented in our database. Teaching is measured by the average number of medical specialists trained in the hospital.

As a last output variable, a dummy for the existence of an emergency department is included. A dummy variable is chosen for two reasons. First, the availability of the emergency department and the number of specialists and nurses working there is important in itself, even if no patients turn up. Second, the registration of the production of emergency departments is of poor quality and therefore underestimated by the available data.

\section{Departments}

The outputs of similar departments in different hospitals are more homogeneous than the outputs of total hospitals. The outputs of hospital departments are equal to the outputs charged to patients and insurance companies. Therefore the outputs per department used in this study are reliable and valid measures. The outputs per department are briefly discussed.

Ward The most straightforward production of the ward is the number of ward days. Ward days can be subdivided into ward days in an inpatient setting, a day care setting and an intensive care setting. Since previous studies have shown that the workload differs between the first ward day and subsequent ward days, four different categories of ward days are distinguished:

- first ward days;

- following ward days;

- day care ward days;

- intensive care ward days.

The outputs require inputs from all four different categories of staff. Therefore four input prices are distinguished as input measures for the ward.

Outpatient department Most patients start their treatment in a hospital by visiting the outpatient department. Follow-up treatments and check-ups are also performed in the outpatient department. Small operations, such as vasectomy, are increasingly performed in outpatient departments as well. To summarise, we distinguish three different output measures: 
- first outpatient visits;

- other outpatient visits;

- small operations.

The operations are weighted by the operation's tariff. These tariffs are determined by the Dutch Central Organisation on Tariffs. The outpatient department staff consists mostly of general staff, support staff and nurses. The prices of these three kinds of staff are used for this department.

Operating theatre Most operations are performed in the operating theatre. We use the weighted number of operations performed as an output measure of the operating theatre. These operations are weighted by their tariffs. In the operating theatre, staff inputs consist mostly of nurses, general staff and support staff. The prices of these three categories of staff are used for this department.

Radiology The radiology department produces X-rays. We use the total number of X-rays, including MRI- and CTscans, as output measures. X-rays are weighted by their tariffs. In the radiology department, the staff in most hospitals consists of general staff and support staff. The prices of these two categories of staff are used for this department.

Laboratory Two types of laboratories can be distinguished: the clinical chemistry laboratory and the pathology laboratory. We include only the clinical chemistry laboratory, because too few hospitals possess a pathology laboratory. The outputs for the laboratory are lab-tests. Lab-tests are weighted by their tariffs. Laboratory staff in most hospitals consists of support staff and general staff. The prices of these two categories of staff are used for this department.

Physiotherapy The physiotherapy department consists mainly of occupational and physical therapists. The main output of the physiotherapy department is hours of individual physiotherapeutic treatment. Next to individual physiotherapeutic treatments, other outputs, such as physiotherapeutic research and physiotherapeutic treatment in groups, are produced. These outputs are taken together and weighted by their tariffs to form one output measure. In the physiotherapy department, the staff in most hospitals consists of support staff and general staff. The prices of these two categories of staff are used for this department.

\section{Quality}

There are a few indicators that are widely recognised as measures of quality. These indicators mostly measure outcome and include, for example, the number of re-admissions, death-rates and complications. In fact, they measure quality as the outcome of the medical process. Davies and
Crombie [8] give two reasons why outcomes as a measure of quality should be treated with care. First, outcome indicators depend on case mix. Hospitals treating more complicated diseases have higher death- and complication-rates, irrespective of their quality. When the quality of the whole hospital is the unit of measurement, case-mix-adjusted quality measures are needed. Second, outcome indicators have less than optimal validity and reliability as they are often hard to measure. Third, as shown by Mant and Hicks [22], outcome indicators can fail to reveal process differences. For example, big differences in processes for the treatment of acute myocardial infarction are not found when comparing death rates. Even when a process is known to be better, death-rates do not show these differences.

Because of the disadvantages of outcome indicators, process indicators have become more important as a measure of quality of health care. In this study we use process indicators as measures of quality. We use the quality measures developed by the Dutch weekly paper Elsevier [10]. Elsevier is a large Dutch news weekly, comparable to Time or Newsweek. Elsevier has measured quality since 1997. Between 1997 and 2001, only one-half or less of Dutch hospitals were included in the study. Since 2002 the percentage of participating hospitals has increased to approximately $80 \%$ of all Dutch hospitals. Quality is measured by a survey conducted among general practitioners (GPs), the medical staff, nurses and managers of the hospital. These stakeholders are best informed about the quality of the hospital. They can help reduce the information asymmetry between the patient and the hospital. Each of these stakeholders is asked a number of questions about the hospital they are involved with. On every question they are asked whether the situation is appropriate to their hospital. A hospital receives 1 point if, on a positive item, 20-32\% of the respondents perceive it as being appropriate, 2 points if between 33 and $49 \%$ of the respondents find the situation appropriate, and 3 points if $50 \%$ or more find the situation appropriate. On weak items the same holds with negative scores. In 2004, the survey was divided into four factors:

- Medical and nursing quality (quality of the emergency department, operating theatre, nursing staff).

- Organisational quality (well organised and a good employer).

- Quality of care process (cooperation with GPs and nursing homes).

- Quality of patient care (patient friendly).

- Factor 1: Medical and nursing quality is measured by six positively and two negatively formulated questions. The score on this factor is therefore between -6 and 18. Questions in this part of the survey refer to medical and nursing expertise, quality of the operating theatre and medical mistakes. 
- Factor 2: Organisational quality is measured by six positively and six negatively formulated questions. The score on this factor is therefore between -18 and +18 . Question on this part of the survey refer to: quality of management, quality of information technology (IT), preparation for changing demographic factors (growing age of the population), bad financial situation, internal problems, and lack of staff.

- Factor 3: Quality of the care process is measured by six positively and three negatively formulated items. The score on this factor is therefore between -9 and 18 . Questions in this part of the survey refer to: cooperation with general practitioners and nursing homes, good coordination with general practitioners, slow and arrogant medical specialists.

- Factor 4: Quality of patient care is measured by eight positively and two negatively formulated questions. The score on this factor can therefore be between -6 and 24. Questions in this part of the survey refer to: being friendly to the patient, appreciated by the patient, friendly staff, patient-friendly planning and length of waiting lists.

In 2004 , the questionnaire was sent to 5,578 respondents, of which $25 \%$ replied. At least 15 respondents are required before the results of a hospital are presented. In earlier years fewer factors and questions were used. Moreover, in 2004, more hospitals were included. Because of these two reasons we use the outcomes of the year 2004 as quality measures in this study. Using the quality measure of just 1 year comes with the disadvantage of assuming quality does not change over time. We prefer using the better quality data of 2004 over using a time varying measure that is available for fewer hospitals and is of lesser quality. We use all four quality factors as efficiencyexplaining variables in this study.

\section{Econometric methods}

This study uses stochastic frontier analysis (SFA) as developed by Aigner et al. [1] for estimation. The SFA technique was developed to estimate firm and time varying efficiency levels. A stochastic frontier equation, based on panel data, can be written as follows:

$y_{i t}=f\left(x_{i t} ; \beta\right) * \exp \left(v_{i t}\right) * \mathrm{TE}_{i t}$

where $\left[f\left(x_{i t} ; \beta\right) * \exp \left(v_{i t}\right)\right]$ is the stochastic frontier (see Kumbhakar and Lovell [18] for a more detailed description). $\mathrm{TE}_{i t}$ measures technical efficiency of firm $i$ at time $t$. $\mathrm{TE}_{i t}$ can be any value between zero and one.

This study uses panel data. The use of panel data in a stochastic frontier model has a number of methodological advantages over cross-section data. Linna [20] shows that hospital efficiency estimates are more plausible when using panel data compared to cross-sectional data. Further, Jondrow et al. [17] show that consistency issues arise with individual efficiency scores in a cross-section approach.

We have to choose a functional form for $f\left(x_{i t} ; \beta\right)$. This study uses a Cobb-Douglas cost function. In other studies the translog cost function, which is an extension of the Cobb-Douglas cost function, has been used [20, 28]. The advantage of the translog cost function over the CobbDouglas function is its flexibility. Whether to use translog or Cobb-Douglas is an issue addressed by a number of studies. Some studies in the hospital sector, for example Rosko [27], conduct a formal test of the Cobb-Douglas specification and reject this specification. Mortimer and Peacock [24] found no statistical justification for the translog function. We also estimated a translog model. However, some of these models did not converge. As argued by Mortimer and Peacock [24], Cobb-Douglas is better because of parsimony. Latruffe et al. [19] further argue that: "Translog tends to be over specified when limited data are available". Some of our translog estimations indeed did not converge. Therefore, we use the CobbDouglas function in this study.

The Cobb-Douglas cost function reads as:

$$
\begin{aligned}
& \ln \frac{\mathrm{TC}_{k, i t}}{w_{t}}=\alpha_{k, 0}+\sum_{l=1}^{m_{k}} \alpha_{k, l} Y_{k l, i t}+\sum_{j=1}^{q_{k}} \beta_{k, j} \ln \frac{P_{j, i t}}{w_{t}}+\varepsilon_{k, i t} \\
& \forall k=1, \ldots, 6 \quad \forall i=1, \ldots, N_{k} \quad \forall t=1, \ldots, T_{k, i}
\end{aligned}
$$

where

$k$ counter for departments, $k=1$ for the total hospital

$m_{k} \quad$ number of products for department $k . m_{k}=4$ for the ward, 3 for the outpatient department, 1 in the other departments

$q_{k} \quad$ number of price parameters included for department $k$, see data section

$N_{k} \quad$ number of observations for department $k$

$T_{k, i} \quad$ number of time periods available for department $k$ and hospital $i$. Maximum is 4 for radiology and 5 for all other departments

$\mathrm{TC}_{k, i t}$ costs of department $k$ in hospital $i$ in year $t$, $\forall k=1, \ldots, 6 i=1, \ldots, N_{k}, t=1, \ldots, T_{k, i}$

$Y_{k l, i t} \quad$ production of product $l$ in department $k$ for hospital $i$ in year $t$

$\forall k \quad 1, \ldots, 6 i=1, \ldots, N_{k}, t=1, \ldots, T_{k, i}, l=1, \ldots, m_{k}$

$P_{j, i t} \quad$ price of input factor $j$ in department $k$ for hospital $i$ in year $t$

$\forall j \quad 1, \ldots, q_{k} \forall k=1, \ldots, 6 i=1, \ldots, N, t=1, \ldots, T_{i}$

$w_{t} \quad$ price of input factor $j$ in department $k$ for hospital $i$ in year $t, \forall t=1, \ldots, 5$ 
$\varepsilon_{k, i t} \quad$ Error term for department $k$ in hospital $i$ at time $t$, $\forall k=1, \ldots, 6 i=1, \ldots, N_{k}, t=1, \ldots, T_{k, i}$

$\alpha_{k, o}, \alpha_{k, l}, \beta_{k, j}$, are parameters to be estimated.

Assuming that:

$\varepsilon_{k, i t}=u_{k, i}+v_{k, i t} \quad \forall k=1, \ldots, 6$

$v_{k, i t} \sim \mathrm{N}\left(0, \sigma_{v, k}^{2}\right)$ represents random statistical noise.

$u_{k, i} \sim \mathrm{N}^{+}\left(\mu, \sigma_{u, k}^{2}\right) \quad$ represents time-invariant cost inefficiency.

The specification in Eqs. 1-3 leads to a stochastic frontier approach with efficiency varying for each department per hospital, but assumed to be constant over time. To estimate time-varying efficiency, the parameterisation introduced by Battese and Coelli [3] is used.

$$
\begin{aligned}
& u_{k, i t}=\eta_{k, i t} u_{k, i}=\left\{\exp \left[-\eta_{k}\left(t-T_{i}\right]\right\} u_{i}\right. \\
& \forall k=1, \ldots, 6 i=1, \ldots, N_{k}, t=1, \ldots, T_{k, i}
\end{aligned}
$$

$u_{k, i t}$ is time variant inefficiency and $\eta_{k}$ is parameters to be estimated.

The parameterization in Eq. 4 requires one additional parameter to be estimated. This parameterisation allows for the efficiency parameter $\mu_{k, i t}$ to remain constant, increase or decrease over time. The $\eta_{k}$ parameters describe whether the efficiency of a department has increased $\left(\eta_{k}>0\right)$ or decreased $\left(\eta_{k}<0\right)$. To test whether the efficiency change is significant $\left(\eta_{k}<>0\right)$, it suffices to apply a $t$ test.

The efficiency at time $t$ of department $k$ in hospital $i$, is calculated as follows

$\operatorname{Eff}_{k, i t}=\exp \left(u_{k, i t}\right)$.

To explain efficiency, Battese and Coelli [4] developed a one-stage model. We estimated this one-stage model. This model did not converge. We therefore decided to use a less sophisticated two-stage model. The first stage is the model described in Eqs. 1-5. In the second stage we perform a separate regression analysis to explain efficiency. We regress the expected value of the efficiency parameters (Eq. 6) on our set of quality variables.

$\operatorname{Eff}_{i}=\alpha_{0}+\sum_{j=1}^{4} \beta_{j}$ quality $_{j, i}+\varepsilon_{i}$

$\operatorname{Eff}_{i}=\sum_{i=1}^{T_{i}} \operatorname{Eff}_{i t} / T_{i}, \forall i$

Quality $_{j, i}$ is the quality measure for the $j$-th quality variable for the $i$-th hospital, $\alpha_{0}, \beta_{j}$ are parameters to be estimated.

We perform a comparable analysis for the departments:

$\operatorname{Eff}_{i, t}=\alpha_{0}+\sum_{k=1}^{6} \beta_{k} \operatorname{Eff}_{k, i t}+\varepsilon_{i, t}$.

\section{Estimation}

The program frontier 4.1 developed by Coelli [7] is used to estimate the parameters in Eqs. 2-4. This program uses a maximum likelihood approach with OLS estimates as starting values. According to Schmidt and Sickles [29], the advantage is that these ML-estimators are consistent and asymptotically efficient as $\mathrm{N} \rightarrow \infty$, regardless of $\mathrm{T}$. Another advantage of the maximum likelihood approach is the ability to perform statistical tests.

The estimation procedure is performed for the total hospital and the six different departments. To improve the estimation procedure, instead of maximising with respect to the parameters $\sigma_{u}^{2}$ and $\sigma_{v}^{2}$, the program maximises the likelihood equation using the parameters $\gamma$ and $S^{2}$, where

$$
\begin{array}{r}
\gamma=\sigma_{\mu}^{2} /\left(\sigma_{u}^{2}+\sigma_{v}^{2}\right) \\
S^{2}=\sigma_{v}^{2}+\sigma_{u}^{2} .
\end{array}
$$

Testing the significance of the parameter $\gamma$, i.e. testing the significance of $\sigma_{u}^{2}$, shows whether a stochastic frontier function is required at all.

After this maximisation procedure, estimators can be derived for $\sigma_{\mu}^{2}$ and $\sigma_{v}^{2}$ from Eq. 6 .

The efficiency for department $k$ in hospital $i$ at time $t$ can be estimated by

$\operatorname{Eff}_{k, i t}=1 / \exp \left(u_{k, i t}\right)$.

Equation 9 finally provides the efficiency estimation for both total hospital organisations and individual departments.

\section{Estimation results}

The variables, and their descriptive statistics, used in this study are listed in Table 1.

The figures in Table 1 reflect the increasing costs per hospital in the Netherlands. This is a consequence of the decreasing number of hospitals, an increasing production, and increasing salaries. Hospitals still vary considerably in size. The costs between the smallest and the largest hospital in our database vary by a factor 10 . Variation between hospitals is also seen in quality scores. The difference between the minimum and maximum scores on all four quality measures is about 20; the standard deviation is around 4 for all measures. These results show that professionals perceive significant differences in quality between hospitals. Both quality and costs vary between hospitals and hospital departments. The SFA must answer the questions to what extent efficiency affects the increase 
in hospitals' costs over time, and to what extent quality and departmental efficiency are related to hospital efficiency.

Table 1 further presents the average costs per treatment in the different departments after the removal of outliers (5\% of the departments with the highest and 5\% with the lowest prices per output measure). This removal is necessary since we see variations in prices per output measure between years within hospitals that are between 2 and 10: i.e. $200-1,000 \%$ price changes between years. For the physiotherapy department, these fluctuations are sometimes even higher. These outliers are removed from the data. The remainder of this section presents the results of the efficiency analysis based on the data without outliers.

Table 2 presents the results of the SFA for the total hospital and six individual departments. The parameters that represent the production in the total hospital estimations is highly significant $(P<0.01)$. The parameter estimate for the weighted admission is approximately four times as high as the parameter estimate for day-care, and three times as high as the parameter estimate for outpatients. The total of the parameter estimates for the production measures are approximately equal to 1 . This indicates the absence of both diseconomies and economies of scale in Dutch hospitals. The parameter $\mu$ is statistically significant. This shows that an 'ordinary' $\mathrm{N}^{+}\left(0, \sigma_{\mu}\right)$ distribution is rejected. Efficiency is estimated by the parameters $\gamma$ and $S^{2}$, see Eq. 5. Based on this equation, the error component $\left(\sigma_{\mathrm{v}}\right)$ and efficiency component $\left(\sigma_{\mu}\right)$ can be calculated. $\sigma_{\mu}$ exceeds $\sigma_{\mathrm{v}}$ by more than a factor of 50. This indicates that inefficiency plays a bigger role than random variation. Together with the significance of the estimates for $\gamma$, which measures the relative size of $\sigma_{\mu}$ compared to $\sigma_{\mathrm{v}}$, this suggests that inefficiency exists in Dutch hospitals and that there are differences in inefficiency between Dutch hospitals.

Table 2 further shows the results for individual departments separately. The parameters representing the production variables are statistically significant $(P<0.01)$ for all departments. This suggests that the production parameters distinguished in this study reflect true differences in the production of the departments. This is also shown by the $R^{2}$-measures for the OLS-equations, which vary between 0.76 and 0.95 . The price parameters provide a less consistent picture. Most estimates are not statistically significant at the 5\% level. Some parameter estimates are even

Table 1 Descriptive statistics of variables used in this study

\begin{tabular}{|c|c|c|c|c|c|c|}
\hline & Min & Max & Mean & $\mathrm{SD}$ & Mean 1998 & Mean 2002 \\
\hline \multicolumn{7}{|l|}{ Dependent variable } \\
\hline Total costs $(€ 1,000)$ & 12,910 & 217,056 & 61,280 & 34,327 & 50,589 & 76,351 \\
\hline \multicolumn{7}{|l|}{ Explanatory variables } \\
\hline Length of stay & 4.7 & 11.3 & 8.1 & 1.0 & 8.7 & 7.3 \\
\hline Ward days & 29,112 & 302,328 & 108,921 & 52,256 & 113,390 & 104,924 \\
\hline Day-care & 1,838 & 24,921 & 7,658 & 3,795 & 6,369 & 9,568 \\
\hline Admissions & 3,597 & 36,576 & 13,257 & 5,897 & 12,778 & 14,291 \\
\hline Ambulatory care patients & 18,551 & 227,531 & 75,927 & 34,775 & 60,781 & 85,405 \\
\hline Clinical DRG-weight & 0.76 & 1.32 & 0.94 & 0.09 & 0.92 & 0.95 \\
\hline \multicolumn{7}{|l|}{ Average costs } \\
\hline Cost per patient (inpatient + day-care) & 1,784 & 4,689 & 2,817 & 512 & 2,555 & 3,101 \\
\hline Costs per average DRG (inpatient) & 2,999 & 7,151 & 4,754 & 749 & 4,158 & 5,460 \\
\hline \multicolumn{7}{|l|}{ Quality variables } \\
\hline Care & 0 & 17 & 9.5 & 3.9 & & \\
\hline Organisation & -3 & 15 & 4.9 & 3.2 & & \\
\hline Cooperation & -5 & 13 & 3.8 & 4.2 & & \\
\hline Patient friendly & -3 & 16 & 6.2 & 4.1 & & \\
\hline \multicolumn{7}{|l|}{ Cost prices intermediate products } \\
\hline Ward & 216 & 377 & 290 & 43 & 195 & 256 \\
\hline Outpatient & 38 & 113 & 78 & 17 & 80 & 85 \\
\hline Operating theatre & 611 & 1,282 & 918 & 160 & 952 & 957 \\
\hline Radiology & 0.81 & 1.18 & 0.97 & 0.09 & & 0.95 \\
\hline Laboratory & 1.80 & 3.69 & 2.52 & 0.43 & 102 & 106 \\
\hline Physiotherapy & 0.8 & 3.1 & 1.3 & 0.4 & 1.13 & 1.45 \\
\hline
\end{tabular}

$D R G$ Diagnostic related group 
statistically non-significant or negative. This is probably due to multicollinearity in the price variables. All correlation coefficients between the price variables are statistically significant and positive and vary between 0.08 for the correlation between the price of students and support staff, and 0.43 between the price of support staff and nurses. The statistically significant parameter estimates confirm our expectations. The price of nurses significantly influences the costs of the ward. The price of technical staff has a significant effect on the costs of the operating theatre, the laboratory and the physiotherapy department.

The significance of the efficiency differences of the departments between hospitals is measured by the significance of the parameter estimate for $\gamma$. The finding that $\gamma$ is highly statistically $(P<0.01)$ significant for all departments leads to the conclusion that efficiency differences of hospital departments between hospitals exist. The finding that $\sigma_{\mu}$, which measures the variation in efficiency, is much (at least a factor 35) larger than $\sigma_{v}$, which measures random variation, adds to this conclusion. The conclusion holds for all six departments included in this study: ward, outpatient, operating theatre, radiology, laboratory and physiotherapy.

To obtain more insight into the variation in efficiency between departments Table 3 presents the mean efficiency estimates for the six different departments. The highest mean efficiency, namely $85 \%$, is found for the ward. The lowest mean efficiency is found for the outpatient department $(70 \%)$.

Table 3 further presents the change in efficiency over time, measured by the parameter $\eta$. Two departments, the operating theatre and the laboratory, increased their efficiency over time. Compared to other departments, these two are less dependent on staff ( $46 \%$ of both departments). The other departments show a decreasing efficiency over time. The estimated time varying efficiency change is significant for both the ward and the physiotherapy

Table 2 Parameter estimates of stochastic frontier analysis (SFA; $t$ values in brackets)

\begin{tabular}{|c|c|c|c|c|c|c|c|}
\hline & Total hospital & Ward & Outpatient & $\begin{array}{l}\text { Operating } \\
\text { theatre }\end{array}$ & Radiology & Laboratory & Physiotherapy \\
\hline No. of observations & & 258 & 282 & 278 & 173 & 193 & 237 \\
\hline \multicolumn{8}{|c|}{ Explanatory variables (production) } \\
\hline (Weighted) admissions & $0.64(20.34)$ & & & & & & \\
\hline (Weighted) day-care & $0.14(6.03)$ & & & & & & \\
\hline First outpatient visit & $0.23(8.6)$ & & & & & & \\
\hline Education & $0(3.23)$ & & & & & & \\
\hline First-aid & $0.01(1.01)$ & & & & & & \\
\hline First ward day & & $0.41(5.8)$ & & & & & \\
\hline Other ward days & & $0.40(7.0)$ & & & & & \\
\hline Day-care & & $0.25(5.53)$ & & & & & \\
\hline First outpatient visit & & & $0.52(6.3)$ & & & & \\
\hline Other outpatient visit & & & $0.49(6.6)$ & & & & \\
\hline Weighted procedure & & & $0.01(0.2)$ & & & & \\
\hline Weighted operations & & & & $0.87(26.3)$ & & & \\
\hline Weighted X-rays & & & & & $0.99(38.9)$ & & \\
\hline Weighted lab-research & & & & & & $0.88(33.3)$ & \\
\hline Weighted physio hours & & & & & & & $0.8(15.0)$ \\
\hline \multicolumn{8}{|c|}{ Explaining variables (prices) } \\
\hline P_general_staff & $0.35(4.52)$ & $0.23(2.8)$ & $0.33(2.5)$ & $-0.06(-0.4)$ & $-0.07(-0.7)$ & $-0.13(-1.2)$ & $0.09(0.5)$ \\
\hline P_nurses & $0.13(3.0)$ & $0.43(3.8)$ & $0.81(4.9)$ & $0.22(1.3)$ & & & \\
\hline P_Students & & $0.01(0.8)$ & & & & & \\
\hline P_support & $-0.02(-0.4)$ & $0.06(0.5)$ & $0.22(1.7)$ & 0.29 (1.9) & 0.19 (1.6) & $0.42(2.4)$ & $0.63(2.0)$ \\
\hline \multicolumn{8}{|c|}{ Variables explaining efficiency } \\
\hline$\sigma^{2}$ & $0.01(5.2)$ & $0.02(4.6)$ & $0.07(5.8)$ & $0.04(4.9)$ & $0.02(5.2)$ & $0.03(4.6)$ & $0.19(2.6)$ \\
\hline$\gamma$ & $0.79(30.1)$ & $0.66(13.3)$ & $0.78(24.2)$ & $0.73(11.7)$ & $0.68(12.8)$ & $0.82(17.9)$ & $0.88(19.0)$ \\
\hline$\mu$ & $0.17(6.4)$ & $0.21(5.6)$ & $0.48(8.6)$ & $0.31(4.2)$ & $0.21(4.8)$ & $0.3(4.3)$ & $0.42(2.0)$ \\
\hline$v$ & $-0.02(0.8)$ & $-0.12(2.8)$ & $-0.03(1.6)$ & $0.01(0.4)$ & $-0.01(0.2)$ & $0.01(0.3)$ & $-0.09(3.5)$ \\
\hline$\sigma_{v}$ & 0.01 & 0.011 & 0.057 & 0.028 & 0.011 & 0.024 & 0.168 \\
\hline$\sigma_{\mu}$ & 0.78 & 0.649 & 0.725 & 0.704 & 0.671 & 0.791 & 0.715 \\
\hline
\end{tabular}


Table 3 Mean efficiency per department per year

\begin{tabular}{|c|c|c|c|c|c|c|}
\hline Department & $1998(\%)$ & $1999(\%)$ & $2000(\%)$ & $2001(\%)$ & $2002(\%)$ & Total $(\%)$ \\
\hline Ward & 88.4 & 86.5 & 84.8 & 83.1 & 81.1 & 84.9 \\
\hline Outpatient & 64.4 & 62.8 & 61.6 & 59.7 & 60.0 & 61.8 \\
\hline Operating theatre & 72.0 & 73.5 & 73.4 & 72.4 & 71.5 & 72.6 \\
\hline Radiology & N/A & 81.6 & 80.5 & 80.8 & 79.8 & 80.7 \\
\hline Laboratory & 75.7 & 74.2 & 73.7 & 73.6 & 72.9 & 74.0 \\
\hline Physiotherapy & 74.7 & 73.4 & 70.5 & 67.7 & 64.3 & 69.9 \\
\hline
\end{tabular}

department. The processes of these departments depend more on staff (73 and $77 \%$ of costs, respectively), and therefore efficiency gains are probably more difficult to achieve.

Table 4 presents the relationship between efficiency and quality of the hospital. Table 4 shows that three out of four quality parameters are positively and statistically significant correlated to efficiency. The fourth parameter, quality of care, is correlated negatively with efficiency but this is not statistically significant. This indicates that more efficient hospitals also are better organised, have a better cooperation with other health care providers, and are more patient friendly.

Table 4 further presents the results of the regression analysis where efficiency is the dependent variable and the quality variables are the explanatory variables. In the regression analysis, only one of the individual efficiency parameter estimates, the parameter estimate for patient friendly treatment, is positive and statistically significantly different from 0 . The lack of statistical significance in the regression analysis for variables that are statistically significantly correlated with efficiency can be explained by multicollinearity. The four quality variables together explain $15.8 \%$ (adjusted $R^{2}=0.158$ ) of the inefficiency of hospitals. This $15.8 \%$ can be interpreted as maximum possible savings that can be realized by improving quality. This is an interesting figure, especially considering that the annual costs of general hospitals are about $€ 10$ billion.

Table 5 presents the correlation coefficients between the efficiency estimates of the total hospital and the efficiency estimates of the individual department. Table 5 shows that the correlations between the efficiency of the different departments and the total hospital are all below 0.40 . The efficiency of the ward, the outpatient department and the operating theatre are significantly and positively correlated with the efficiency of the total hospital. The efficiency of the outpatient department, the radiology and the laboratory are not significantly correlated with the efficiency of the hospital. The mutual correlations between the efficiency estimates of the departments are all below 0.32 , and 10 out of 15 correlation estimates are not statistically significant.

Our general conclusion is that the efficiency of departments in a hospital is mostly independent of the efficiency of other departments in the same hospital, and is independent of the efficiency of the total hospital. The departmental efficiency is, for three out of six departments, not statistically significantly correlated with the efficiency of the total hospital. For departments whose efficiency is significantly correlated with hospital efficiency, the correlation coefficient is less than 0.45 .

As described in the Introduction, this lack of relationship between the efficiency of departments and the efficiency of the total hospital can be explained by the fact that departments and hospitals do not strive toward common goals. It seems that departments have an incentive to maximise the efficiency of their department, which may conflict with maximising efficiency at the hospital level. Whether this is really the case can be tested. If the lack of a relationship between hospital efficiency and departmental efficiency is due to poor cooperation as we presume, we expect that a high efficiency score for departments and a low efficiency for the total hospital goes together with low

Table 4 Correlations and regressions of mean efficiency on four quality variables

\begin{tabular}{|c|c|c|c|c|c|}
\hline & \multicolumn{2}{|l|}{ Correlation } & \multicolumn{3}{|l|}{ Regression } \\
\hline & Correlation coefficient & $P$ value & Beta & $t$ value & $P$ value \\
\hline Constant & & & $8.02 \mathrm{E}-01$ & 34.42 & 0.00 \\
\hline Patient friendly & 0.35 & 0.00 & 4.67E-03 & 2.08 & 0.04 \\
\hline Cooperation & 0.28 & 0.01 & $2.06 \mathrm{E}-03$ & 0.72 & 0.47 \\
\hline Organisation & 0.21 & 0.06 & $2.14 \mathrm{E}-03$ & 0.84 & 0.41 \\
\hline Care & -0.10 & 0.39 & $-3.26 \mathrm{E}-03$ & -1.54 & 0.13 \\
\hline
\end{tabular}


Table 5 Correlations between efficiency of departments and the total hospital

\begin{tabular}{|c|c|c|c|c|c|c|c|}
\hline Department & & Total & Ward & Outpatient & Operating theatre & Radiology & $\overline{\text { Laboratory }}$ \\
\hline \multirow[t]{2}{*}{ Ward } & Correlation & 0.29 & & & & & \\
\hline & $P$ value & 0.00 & & & & & \\
\hline \multirow[t]{2}{*}{ Outpatient } & Correlation & 0.09 & -0.01 & & & & \\
\hline & $P$ value & 0.11 & 0.87 & & & & \\
\hline \multirow[t]{2}{*}{ Operating theatre } & Correlation & 0.40 & 0.14 & -0.13 & & & \\
\hline & $P$ value & 0.00 & 0.06 & 0.04 & & & \\
\hline \multirow[t]{2}{*}{ Radiology } & Correlation & 0.12 & 0.03 & 0.16 & -0.01 & & \\
\hline & $P$ value & 0.12 & 0.74 & 0.04 & 0.90 & & \\
\hline \multirow[t]{2}{*}{ Laboratory } & Correlation & -0.01 & 0.00 & 0.05 & 0.10 & -0.03 & \\
\hline & $P$ value & 0.87 & 0.95 & 0.51 & 0.19 & 0.74 & \\
\hline \multirow[t]{2}{*}{ Physiotherapy } & Correlation & 0.31 & 0.24 & -0.02 & 0.32 & 0.02 & 0.25 \\
\hline & $P$ value & 0.00 & 0.00 & 0.72 & 0.00 & 0.83 & 0.00 \\
\hline
\end{tabular}

cooperation. Cooperation is one of the quality variables in this study. Table 6 provides the scores for this variable for four groups of hospitals. These groups are based on the efficiency scores of the total hospital organisation and of the departments of these hospitals. Hospitals are divided into two groups on both variables: $50 \%$ of the hospitals with the highest scores in group 1, 50\% with the lowest scores in group 2.

As we can see from Table 6 , hospitals that have both high total hospital efficiency and high departmental efficiency also have the highest score on variable cooperation. The group of hospitals with low efficiency of both total hospital and departments scores second best. We see an interaction between hospital efficiency and departmental efficiency on the cooperation score. The statistical effect of this interaction can be tested by a simple Anova $F$-test. This $F$-test shows that both the efficiency of the hospital and the efficiency of the department have no statistically significant relationship with cooperation. However, the interaction effect is significant on the 5\% level $(P=0.41)$. This result confirms our expectation that departments with a high efficiency within a hospital with a low efficiency at the hospital level show worst cooperation. Cooperation is a key issue for hospitals to achieve high efficiency both on total hospital level and department level.

Table 6 Score of quality measure cooperation in high and low hospital and department efficiency groups

\begin{tabular}{lll}
\hline & \multicolumn{2}{l}{ Efficiency of total hospital } \\
\hline Efficiency of departments & High & Low \\
High & $5.7(0.6)$ & $3.1(0.9)$ \\
Low & $4.5(0.8)$ & $5.1(0.7)$ \\
\hline
\end{tabular}

\section{Discussion}

This study analysed the efficiency of hospitals and of hospital departments. Corroborating our first hypothesis as well as the findings of most previous studies, we do not find that efficiency can be explained by a lack of quality. On the contrary, we find that efficiency and quality go together. They are complements rather than substitutes. This provides new evidence that efficiency differences between hospitals cannot be explained simply by quality differences.

We find supportive evidence for our second hypothesis that hospital efficiency differs from departmental efficiency. In most Dutch hospitals, departments are financed for the intermediate products they produce. This leads to an interest that is (partly) different from the interests of the entire hospital. Our results show that cooperation is a key issue in achieving high efficiency in both departmental and the total hospital organisation.

Our third hypothesis was also confirmed: there is hardly any relationship between the efficiency of different hospital departments. First, this finding can be a result of the capitation system of hospitals. Because hospitals receive a budget, efficiency in one department can compensate for inefficiency in another department. Second, this finding could result from the way a hospital is organised [31], because this finding suggests that the inefficiency of departments depends mainly on department managers and less on the general board of the hospital. This idea is supported by our finding that hospitals that score low on departmental efficiency and high on hospital efficiency, and vice versa, score lower on the quality measure cooperation than hospitals that score high on both measures.

Our findings imply that striving for efficiency within hospital departments contributes only partly to improving the efficiency of hospitals. This finding has policy and 
managerial implications, since the organisational and financial structures of Dutch hospitals are often functional and aimed at creating efficient departments. Organisational structures that facilitate efficient treatment of patients are less common. This implies that Dutch hospitals accept inefficiency in their organisations because of their functionalistic structure. In such structures, goals of department managers differ partially from goals of the hospital, since the budgeting system of most Dutch hospitals maximises the efficiency of intermediate products instead of maximising the utility of the total hospital. The changing financing system in Dutch hospitals, where case-mix-based funding is being introduced to replace of financing individual procedures, might help in improving the efficiency of hospitals. Case-mix-based funding might also lead to a client-driven organisational structure for hospitals. However, case-mix-based funding is not sufficient to maximise efficiency. Even in case mix reimbursement systems, the practice is often that third party payers buy packages of often unrelated services to avoid (in the phrasing of health care providers) "cherry picking" [31]. Inefficiency as a result of bad integration of the health care chain inside (and outside) the hospital will disappear only if case mix reimbursement is applied without package buying, and if efficiency and effectiveness is rewarded at the case level and not at the intermediary product level. Applying a combination of case mix and health care chain reimbursement is done on a small scale in a number of countries nowadays. Until now, these are small scale implementations of another reimbursement policy, which could in principle promote integration of the health care chain. However, there is not yet enough evidence that it will really promote integration and prevent the suboptimisation we observe here.

To conclude, if we consider the finding that quality and efficiency go together from an agency perspective, it could be concluded that potential quality problems that may arise because of information asymmetry between hospitals and their patients may not be as harmful as is commonly believed. This conclusion could be true because the interest of the patient (good quality) goes together with the interest of the hospital (efficiency) if the latter has the utility of the patient in mind. Although this is perhaps an unexpected finding in a health care efficiency study, studies in management science, for example Porter and Olmsted Teisberg [26] and Van Merode [31] have already considered that efficiency and quality are complements. Such studies emphasise that the way a hospital is organised, influences both quality and efficiency simultaneously and in the same direction.

Open Access This article is distributed under the terms of the Creative Commons Attribution Noncommercial License which permits any noncommercial use, distribution, and reproduction in any medium, provided the original author(s) and source are credited.

\section{References}

1. Aigner, D., Lovell, C.A.K., Schmidt, P.: Formulation and estimation of stochastic production function models. J. Econom. 6, 21-37 (1977). doi:10.1016/0304-4076(77)90052-5

2. Arrow, K.: The economics of agency. In: Pratt, J., Zeckhauser, R. (eds.) Principals and agents-the structure of business, pp. 37-51. Harvard Business School Press, Boston (1985)

3. Battese, G.E., Coelli, T.J.: Frontier production functions, technical efficiency and panel data with application to paddy farmers in India. J. Prod. Anal. 3, 153-169 (1992). doi:10.1007/BF00158774

4. Battese, G.R., Coelli, T.J.: A Model for technical inefficiency effects in a stochastic frontier production function for panel data. Empir. Econ. 20, 325-332 (1995). doi:10.1007/BF01205442

5. Blank, J.L.T., Eggink, E., Merkies, A.H.Q.M. Between bed and budget (in Dutch). Sociaal en Cultureel Planbureau/Elsevier Bedrijfsinformatie, Den Haag (1998)

6. Centraal Planbureau: Macro Economic Explorations 2007 (in Dutch). Centraal Planbureau, Den Haag (2006)

7. Coelli, T.: A guide to Frontier Version 4.1: A computer program for stochastic frontier production and cost function estimation. CEPA Working Paper 96/07 (1996)

8. Davies, H.T.O., Crombie, I.K.: Assessing the quality of care. BMJ 311, 766 (1995)

9. Dor, A.: Non-minimum cost functions and the stochastic frontier: on applications to healthcare providers. J. Health Econ. 13, 329334 (1994). doi:10.1016/0167-6296(94)90032-9

10. The best hospitals (in Dutch). Elsevier 25 Sep 2004. pp. 36-50. (2004)

11. Fetter, R.B., Shin, Y., Freeman, J.L., Averill, R.F., Thompson, J.D.: Case mix definition by diagnosis-related groups. Med. Care 18(2):1-53 (1980). February Supplement

12. Fizel, J.L., Nunnikhoven, T.S.: The efficiency of nursinghome chains. Appl. Econ. 25, 49-55 (1993). doi:10.1080/ 00036849300000112

13. Hollingsworth, B.: Non parametric and parametric applications measuring efficiency in health care. Health Care Manag. Sci. 6, 203-218 (2003). doi:10.1023/A:1026255523228

14. Herzlinger, R.: Market Driven Health Care. Perseus Books, Cambridge Harvard Business School (1997)

15. Jacobs, R., Dawson, D.: Hospital efficiency targets. Health Econ. 12, 669-684 (2003). doi:10.1002/hec.758

16. Jensen, M., Meckling, W.: Theory of the firm-managerial behavior, agency costs and ownership structure. J. Financ. Econ. 3, 305-360 (1976). doi:10.1016/0304-405X(76)90026-X

17. Jondrow, J., Materov, I., Lovell, K., Schmidt, P. On the estimation of technical inefficiency in the stochastic frontier production function model. J. Econom. 19(2/3), 233-238 (1982). doi: 10.1016/0304-4076(82)90004-5

18. Kumbhakar, S.C., Lovell, C.A.K.: Stochastic Frontier Analysis. Cambridge University Press, Cambridge (2001)

19. Latruffe, L., Balcombe, K., Davidova, S., Zawalinska, K.: Determinants of technical efficiency of crop and livestock farms in Poland. Appl. Econ. 36, 1255-1263 (2004). doi:10.1080/ 0003684042000176793

20. Linna, M.: Measuring cost efficiency with panel data models. Health Econ. 7, 415-427 (1998). doi:10.1002/(SICI)1099-1050 (199808) 7:5<415::AID-HEC357>3.0.CO;2-9

21. Ludwig, M., Groot, W., van Merode, G.G.: Hospital efficiency and transaction costs: a stochastic frontier approach. Soc Sci Med (2009) 
22. Mant, J., Hicks, N.: Detecting differences in quality of care: the sensitivity of measures of process and outcome in treating acute myocardial infarction. BMJ 311, 793-796 (1995)

23. Meeusen, W., van den Broeck, J.: Efficiency estimation from Cobb-Douglas production functions with composed error. Int. Econ. Rev. 18, 435-444 (1977). doi:10.2307/2525757

24. Mortimer, D., Peacock S.: Hospital efficiency measurement: simple ratio's vs frontier methods. Centre for health program evaluation working paper 135 (2002)

25. Newhouse, J.P.: Frontier estimation, how useful a tool for health economics? J. Health Econ. 13, 317-322 (1994). doi:10.1016/ 0167-6296(94)90030-2

26. Porter, M.E., Olmsted Teisberg, E.O.: Redefining competition in health care. Harv. Bus. Rev. 82(6):64-76, 136 (2004)

27. Rosko, M.D.: Cost efficiency of US hospitals: a stochastic frontier approach. Health Econ. 10, 539-551 (2001). doi:10.1002/ hec.607

28. Rosko, M.D., Chillingerian, J.A.: Estimating hospital efficiency: does case mix matter? J. Med. Syst. 23, 57-71 (1999). doi: 10.1023/A:1020823612156
29. Schmidt, P., Sickles, R.C.: Production frontiers and panel data. J. Bus. Econ. Stat. 2,367-374 (1984) doi:10.2307/1391278

30. Skinner, J.: What do stochastic frontier cost functions tell us about inefficiency? J. Health Econ. 13, 323-328 (1994). doi: 10.1016/0167-6296(94)90031-0

31. Van Merode, G.G.: A prelude of the 2004 Antwerp Quality conference: targets and target values: integrating quality management and costing. Accredit. Qual. Assur. 9, 168-171 (2004). doi:10.1007/s00769-003-0731-8

32. Van Merode, G.G., Groothuis, S., Hasman, A.: Enterprise resource planning for hospitals. Int. J. Med. Inform. 73, 493-501 (2004). doi:10.1016/j.ijmedinf.2004.02.007

33. Vandermeulen, L.E., Van Barneveld, E., Visser, J.: Case mix and performance differences in Dutch. Prismant, Utrecht (2004)

34. Zuckerman, S., Hadley, J., Iezzoni, L.: Measuring hospital efficiency with frontier cost functions. J. Health Econ. 13, 255-280 (1994). doi:10.1016/0167-6296(94)90027-2 